\title{
Localized Cutaneous Argyria Mimicking Blue Nevus after Wearing Earrings
}

\author{
Seung Gi Hong, Sun Young Jo, Eun Phil Heo, Ki Woong Ro \\ Department of Dermatology, Samsung Changwon Hospital, Sungkyunkwan University School of Medicine, Changwon, Korea
}

Localized cutaneous argyria is a rare condition in which the skin changes into blue-grey spots due to the absorption of silver. The lesions need to be differentiated from other pigmentary disorders and require radiographic and histological examination for more accurate diagnosis. Scanning electron microscopy and energy dispersive x-ray spectroscopy can be a confirmatory tool in the evaluation of silver elements in biopsy tissue. This report shows the localized cutaneous argyria in earlobe of a 21-year-old woman who wears silver earrings for 10 years. (Ann Dermatol 31(6) 666 668, 2019)

\section{-Keywords-}

Argyria, Blue nevus, Scanning electron microscopy, X-ray emission spectrometry

\section{INTRODUCTION}

Localized cutaneous argyria is a rare condition in which blue-grey pigmentation results from impregnation of the skin by silver particles ${ }^{1}$. Localized cutaneous argyria occurs when skin directly absorbs silver particles and presents as an elliptical blue-gray macule or papule. This clin-

Received June 15, 2018, Revised October 2, 2018, Accepted for publication October 3, 2018

Corresponding author: Ki Woong Ro, Department of Dermatology, Samsung Changwon Hospital, Sungkyunkwan University School of Medicine, 158 Paryong-ro, Masanhoewon-gu, Changwon 51353, Korea. Tel: 82-55-2335280, Fax: 82-55-233-5289, E-mail: rkw3840@gmail.com ORCID: https://orcid.org/0000-0002-5746-8240

This is an Open Access article distributed under the terms of the Creative Commons Attribution Non-Commercial License (http://creativecommons. org/licenses/by-nc/4.0) which permits unrestricted non-commercial use, distribution, and reproduction in any medium, provided the original work is properly cited.

Copyright (c) The Korean Dermatological Association and The Korean Society for Investigative Dermatology ical manifestation is often confused with the angiomas, blue nevi, dysplastic nevi, melanoma in situ and malignant melanoma because of the overlap with melanocytic lesions ${ }^{2}$. Therefore, radiographic and histologic confirmations are recommended for accurate diagnosis. Analysis of the tissue with scanning electron microscopy and energy dispersive x-ray spectroscopy (SEM-EDS) identified silver and provided confirmatory evidence of localized cutaneous argyria ${ }^{2}$. The case of localized cutaneous argyria resulted from the wearing of silver earrings has been seldom reported. The current report shows the localized cutaneous argyria in earlobe, may be caused by silver earrings.

\section{CASE REPORT}

A 21-year-old woman presented with an asymptomatic solitary bluish macule on posterior aspect of right earlobe. For 10 years, the patient had worn earrings on his right earlobe. Then the color of her posterior earlobe has been gradually changed to blue, and thereafter a $0.7 \times 0.7 \mathrm{~cm}$ bluish macule was observed on the posterior aspect of right earlobe (Fig. 1). The clinical impression was blue nevus. A punch biopsy was performed. Sections with hematoxylin and eosin staining revealed that the specimen was normal epidermis and the brown pigmentation was resulted from deposition of foreign substance on the dermal elastic and collagen fibers, and also basement membrane of eccrine sweat glands (Fig. 2A, B). A definitive diagnosis was rendered after SEM-EDS analysis of the tissue demonstrated the presence of silver (Fig. 2C, D). We received the patient's consent form about publishing all photographic materials.

\section{DISCUSSION}

Argyria is a skin discoloration associated with silver ab- 
sorption. The incidence of argyria was highest in 19th and 20th centuries due to the frequent ingestion or topical applications of silver-containing compounds ${ }^{2}$. Today, localized cutaneous argyria has become a relatively rare disease due to a significant reduction in the use of silver-containing medications ${ }^{2}$. However, heavy metals, including silver, can be introduced into the skin inadvertently through occupational exposure, acupuncture, earrings, topical silver medication, or trauma, etc.

Localized cutaneous argyria caused by direct contact of the silver-containing compounds is rarely reported in

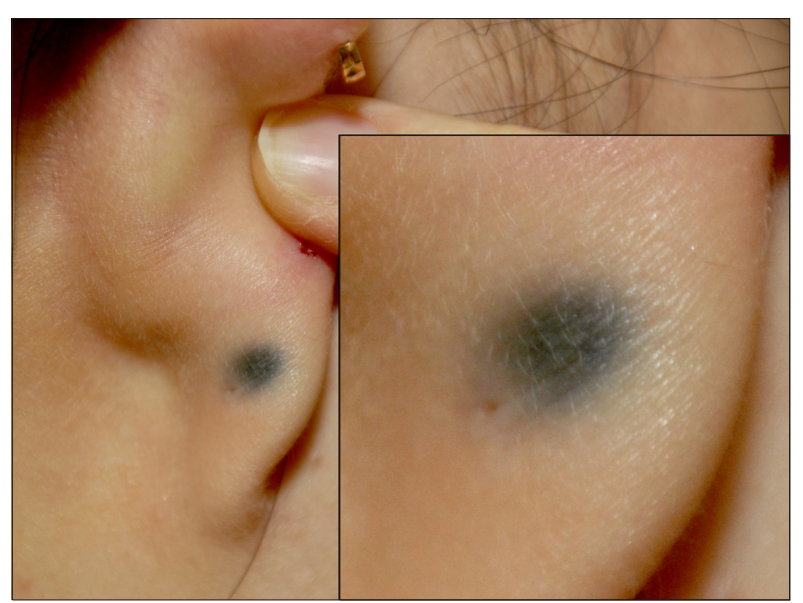

Fig. 1. The patient presented solitary bluish macule on right posterior earlobe.
Korean literatures. To best of our knowledge, total of three cases have been reported. Kwon et al. ${ }^{3}$ have reported two cases of localized cutaneous argyria in hands caused by chemical experiment called silver mirror reaction. Park et al. ${ }^{4}$ have reported one case of localized cutaneous argyria caused by acupuncture.

Localized cutaneous argyria is caused by direct external contact of silver. The most commonly affected areas are the hands, eyes, and the mucosa. Silver is suggested to be deposited in the dermis in a chemically stable and inactive form. It is also believed that argyria occurs through the eccrine sweat ducts because the metal is most concentrated around the secretion site of the sweat glands. However, clear mechanism of the penetration is not known ${ }^{5}$. Argyria represents clinically asymptomatic blue-gray macule or papule with local discoloration similar to melanocyte proliferation ${ }^{6}$. Histologically, the argyria exhibits normal epidermis and multicellular brown streaks and granules. Particularly, in high magnification, those streaks and granules shows interstitial and periadnexal distributions around the secretory coils of the sweat glands or along the elastic fibers of the dermis.

Diagnosis of localized cutaneous argyria is usually obvious due to the location of lesion correlated with specific history and clinical manifestation. The radiography is also recommended for diagnosis by confirming the presence of metallic particles. However, the absence of radiographic evidence does not rule out the diagnosis of disease, since
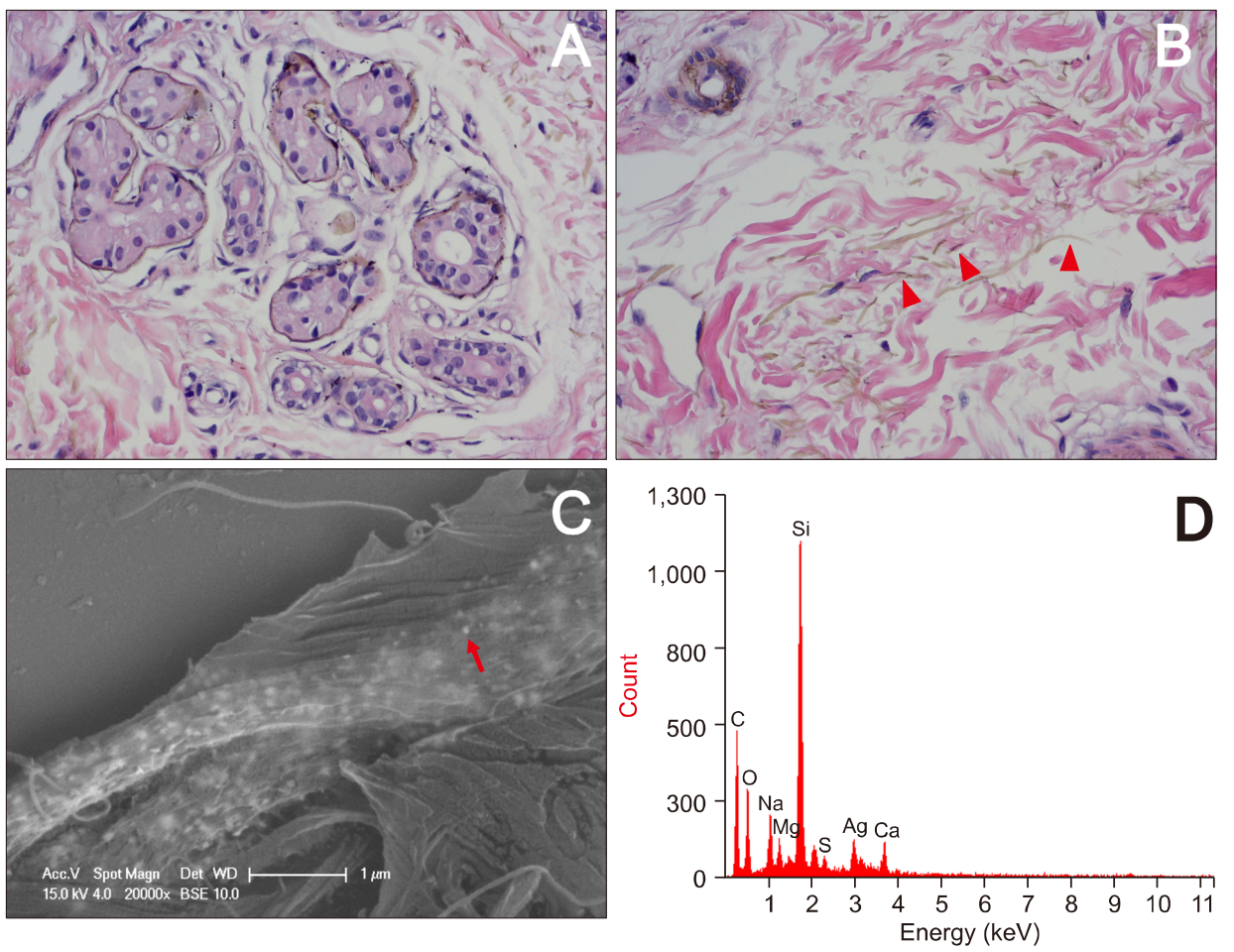

Fig. 2. Microscopic examination of a biopsy specimen from a right earlobe. (A) Discrete, fine, dark granules and deposition of foreign substance on the basement membrane of eccrine sweat glands $(\mathrm{H} \& \mathrm{E}, \times 400)$. (B) Deposition of brown fiber-like foreign substance (arrowheads) on the dermal elastic and collagen fibers $(H \& E, \times 400)$. (C) Scanning electron microscopy demonstrates small white particles (arrow). BSE: backscattered electrons mode. (D) Energy dispersive x-ray spectroscopy analysis identified the particles as minute fragments of silver (Ag) and confirms admixed silica (Si). 
particles are often too fine or widely dispersed to be visible on radiographs. When there is no radiographic evidence, biopsy is recommended to rule out angiomas, blue nevi, dysplastic nevi melanoma in situ and malignant melanoma. Analysis of the tissue with SEM-EDS identified silver and provided confirmatory evidence of localized cutaneous argyria ${ }^{2}$. Microanalytical techniques, such as SEMEDS, can be used to identify chemical elements within a biopsy specimen and establish a definitive diagnosis. SEM exposes a tissue sample to electrons altering the elements at the atomic level and resulting in emission of x-rays, which are measured by EDS. Because individual elements have characteristic emission patterns, the elements are easily identified. SEM-EDS analysis is performed by specialty laboratories and produces accurate results in a timely manner ${ }^{2}$. Once the diagnosis of localized cutaneous argyria has been established, no additional treatment is necessary except for cosmetic reasons. If the pigmentation is cosmetically unacceptable, 5\% hydroquinone, Q-switched 1064-nm neodymium-doped yttrium-aluminium-garnet $(\mathrm{Nd}$ : YAG) laser or surgical excision has been suggested ${ }^{7}$.

We report the case of earring-induced localized cutaneous argyria which was mimicking blue nevus. We performed biopsy for the lesion and prove the localized cutaneous argyria using SEM-EDS techniques. In this manuscript, our patient had worn silver earrings on both earlobes, but argyria occurred only one earlobe. This implies that argyria does not just result from wearing silver earrings. And it is also believed that argyria can be caused by repeated trauma when hanging or pulling the silver earrings. However, further investigation is required. When the clinical feature is a blue nevus without histopathologic evidence of melanocytic proliferation, localized cutaneous argyria should be considered in the differential diagnosis of patients who had been wearing earrings. We report this case with re- view of the literature.

\section{CONFLICTS OF INTEREST}

The authors have nothing to disclose.

\section{ORCID}

Seung Gi Hong, https://orcid.org/0000-0003-0911-3231

Sun Young Jo, https://orcid.org/0000-0002-2881-2671

Eun Phil Heo, https://orcid.org/0000-0002-8576-619X

Ki Woong Ro, https://orcid.org/0000-0002-5746-8240

\section{REFERENCES}

1. Morton CA, Fallowfield M, Kemmett D. Localized argyria caused by silver earrings. Br J Dermatol 1996;135:484-485.

2. McClain CM, Kantrow SM, Abraham JL, Price J, Parker ER, Robbins JB. Localized cutaneous argyria: two case reports and clinicopathologic review. Am J Dermatopathol 2013; 35:e115-e118.

3. Kwon IH, Ryu TH, Kye H, Kim DH, Choi JE, Seo SH, et al. Cutaneous argyria confirmed by scanning electron microscopy and energy dispersive x-ray (SEM-EDX) spectroscopy. Korean J Dermatol 2014;66(Suppl. 1):506-507.

4. Park MY, Jin H, You HS, Shim WH, Kim JM, Kim GW, et al. Localized argyria Troublesome side effect of acupuncture. Korean J Dermatol 2016;68(Suppl. 1):304-305.

5. Garcias-Ladaria J, Hernandez-Bel P, Torregrosa-Calatayud JL, Martínez-Aparicio A. Localized cutaneous argyria: a report of 2 cases. Actas Dermosifiliogr 2013;104:253-254.

6. Hristov AC, High WA, Golitz LE. Localized cutaneous argyria. J Am Acad Dermatol 2011;65:660-661.

7. Park SW, Kim JH, Shin HT, Lee KT, Lee JH, Lee DY, et al. An effective modality for argyria treatment: Q-switched 1,064-nm Nd:YAG laser. Ann Dermatol 2013;25:511-512. 